\title{
Path analysis of core competencies used to predict nurse job performance
}

\author{
Tsair-Wei Chien ${ }^{1}$, Yu Chang ${ }^{2}$, Julie Chi Chow ${ }^{3}$ and Willy Chou ${ }^{4,5 *}$ \\ ${ }^{1}$ Research Department, Chi-Mei Medical Center, Tainan, Taiwan \\ ${ }^{2}$ National Taiwan University School of Medicine, Taiwan \\ ${ }^{3}$ Department of Paediatrics, Chi Mei medical center, Tainan, Taiwan \\ ${ }^{4}$ Department of physical medicine and rehabilitation, Chi Mei medical center, Tainan, Taiwan \\ ${ }^{5}$ Department of Recreation and Health-Care Management \& Institute of recreation, Industry Management, Chia Nan University of Pharmacy, Tainan, Taiwan
}

\begin{abstract}
Objectives: To investigate what types of core competencies predict nurse job performance in a hospital.

Methods: We used the "Nine Competencies Star" competency survey system, developed by the 1111 Job Bank in Taipei, to evaluate 1855 nurses from 3 hospitals in southern Taiwan. A $t$ test was used to examine the mean differences between the 15 core competencies and demographic variables. Exploratory factor analysis was used to determine the number of factors. Path analysis was used to search for factors that affected nurse job performance in a hospital.

Results: The core competencies of the nurses were team cohesion and customer (patient) relationships superior to the public norm. Four factors (teamwork, independence, communication, sympathy) were found and extracted from the 15 studied core competencies. The teamwork property alone predicts nurse job performance in a hospital. However, its predictive effect explains only $3 \%$ of the variance.
\end{abstract}

Conclusions: The explicit core components should be periodically surveyed for healthcare workers to investigate whether the assessment of employee job performance has been closely associated with hospital policy that is beneficial both to the organization and to all of the patients.

\section{Introduction}

The shortage in the nursing workforce in the healthcare industry is a globally important problem [1]. The allocation of working nurses directly and significantly affects patient safety and care quality $[2,3]$ and is closely related to patient treatment outcomes [4-6]. A lack of nurses will lead to negligent care, patient infection, mortality and morbidity, falls, administrative errors, tube displacement, physical restraint and pain, pressure sores, and an increase in the incidence of accidents $[7,8]$. A sufficient supply of nurses is ultimately expected and thus remains an important goal for the healthcare industry [9].

The size and quality of the nursing staff is no longer a decisive pivot qualification used for staffing and recruitment criteria. The core competencies of workers have accordingly been cultivated and developed by the chiefs of human resources management [10-12]. That is why we often neglect implicit personal features (e.g., attitude and motivation), which are types of latent traits that lead to success or failure on the job, in contrast to the explicit features-e.g., professional skills and knowledge certifications-that we can observe [10]. The core competencies have been given names and stipulated definitions in social science and business management studies $[13,14]$.

Registered nurses in clinical practice are vital for the treatment and postoperative care of hospitalized patients. Because of their frequent contact and interaction with patients, nurses are perceived based not only on their professional experience and skills but also on professional nuances that are termed "competency" [13]. This competency has frequently been discussed, is included in management research, and is applied to the field of human resources [14-16]. For example, the competency can refer to nursing recruitment and the selection and promotion of personnel [17]; can help workforce allocation in terms of staffing and development [18]; and can assist in selecting personnel for rewards and promotions based on performance evaluation criteria [19]. All of these require objective measurements for practical application.

Several articles discuss the core competencies of nurses [20,21] and rehabilitation-related therapists [22] in the workplace. Nevertheless, no studies have provided evidence about effective recruitment based on the relevant core competencies in healthcare settings or using these core competencies for nurse selection, staffing, or career development before recruitment. Moreover, no studies have provided unique evidence about the nurse job performance predicted by the core competencies.

The partial least squares structural equation modeling (PLSSEM: covariance based SEM) is most often used in social science [23-26]: management information [27], marketing [28-30], strategic management [31], accounting [32], family business research [31], operational study [32], and organization [33]. Researchers [34] say

Correspondence to: Willy Chou, Chi-Mei Medical Center, 901 Chung Hwa Road, Yung Kung Dist., Tainan 710, Taiwan, E-mail: ufan0101@ms22.hinet.net

Key words: nurse, human resource management, job competency, path analysis

Received: December 03, 2017; Accepted: December 20, 2017; Published: December 22, 2017 
that, to some extent, PLS can replace covariance-based (CB)-SEM in some studies.

In this study, we used the PLS-SEM to investigate (1) what types of core competencies can well predict nurse job performance in a hospital, and (2) what the outline features closely related to hospital policy are.

\section{Methods}

\section{Data source}

We reviewed the data from three Chi-Mei Medical Group hospitals-A ( $n=1290$ nurses), B $(n=686)$, and C $(n=173)$ - of 2149 nurses who had participated, in 2012, in a personal competence project that used the Nine Competencies Star System developed by the 1111 Job Bank in Taipei $[14,35]$. After we had excluded 294 nurses whose annual performance scores were not collected in the study dataset, we finally enrolled the data sets of 1,855 eligible nurses. The Nine Competencies Star System is commonly used in Taiwan not only to help job seekers explore their suitability for certain jobs and careers, but also to assist employers recruit employees that match their requirements [22].

More than 400,000 job seekers (men: 42.67\%; women: 57.24\%; mean age: $28.63 \pm 6.96$ years; $18-30$ years: $69.39 \%$; $31-40$ years: 23.38\%; $41-50$ years: $6.05 \%$; > 51 years: $1.18 \%$ ) have assessed their job competencies on the Nine Competencies Star System website [35]. The public norm data from these assessments were used as a reference for comparisons with the sample in the current study. All of the survey and study processes were approved and monitored by the Chi-Mei Institutional Review Board (IRB).

\section{Fifteen core competencies}

Sixty-six items from the assessment system involving psychological scenarios were assessed by each respondent and then we divided them into 15 core competencies: (i) a need for achievement, (ii) job control, (iii) team cohesion, (iv) conscientiousness, (v) executive ability, (vi) communication, (vii) interpersonal relationships, (viii) empathy, (ix) self-enhancement, (x) adaptability, (xi) stress tolerance, (xii) optimism, (xiii) analytical thinking, (xiv) creativity, and (xv) customer relationships. All of the scenario items without any correct answers were related to each competency, and each competency was assessed using at least 3 items. An example item is: "When encountering a difficult problem to solve, I will (a) avoid it and pretend nothing happened; (b) daringly face and solve it with my own knowledge and skills; (c) seek help from others; (d) prepare a plan to collect data and then solve the problem".

In addition, the reliability and validity of the assessment were taken into account. Any respondent who required more time to answer any single item or repeatedly selected the same response category across items was excluded from the eligible assessment dataset. The Cronbach's a reliability coefficients of the assessed items ranged from 0.70 to 0.79 . The validities were verified with the correlation coefficients between the personal job performance scores and the 15 composite competency scores, which ranged from 0.69 to $0.78(\mathrm{p}<0.001)[35,36]$.

\section{The partial least squares regression method}

In path analysis, the partial least squares (PLS)-SEM method [24, 25] was used to investigate the correlation between components related to the nurse job performance. The path coefficients between any path between the performance and the very component using PLS-SEM were examined using the criterion of type I error at the $p<0.05$ level.
In addition, two graphical forms (path coefficients in the upper panel and independent $t$ values in the bottom) are shown to examine the significance of paths in which the regression coefficients are standardized and range between -1.0 and 1.0. The independent $t$ statistics on the paths were analyzed for some attributes such as the sample size and standard error, which indicate significance if the absolute values are greater than 1.96.

\section{Statistical tools and analyses}

The mean differences across the 15 core components between nurses and the public norm were examined using an independent $t$ test. The number of components that can be extracted and retained were determined using exploratory factor analysis (EFA) and confirmed using the dimension coefficient (DC) [37]. The DC can be obtained using the first three eigenvalues $\left(\theta_{1}, \theta_{2}, \theta_{3}\right)$ extracted from the EFA with the equations:

$$
\begin{aligned}
& \mathrm{Z}=\left(\theta_{1} / \theta_{2}\right) /\left(\theta_{2} / \theta_{3}\right) \text { and } \\
& \mathrm{DC}=\mathrm{Z} /(1+\mathrm{Z}) .
\end{aligned}
$$

The value of the DC is between 0 and 1.0. A higher DC means a stronger tendency toward unidimensionality for a scale. When the DC is greater than 0.67 , the confidence interval (CI) is $>95 \%$, which shows that the data can be measured using a unidimensional scale [37].

PLS path analysis (Smartr-PLS; http://www.pls-sem.com/) was used to determine which nurse job components can be predicted. Furthermore, the determinant components were applied to the three study hospitals to examine (i) whether the predictions are similar when doing a separate analysis for each hospital, and (ii) whether there were significant differences in the path coefficients for each hospital when using the independent $t$ test.

\section{Results}

\section{Descriptive statistics and demographic analysis}

A total eligible sample of 1855 nurses participated in the current study: 1156 (62.32\%) from Hospital A, 577 (31.11\%) from Hospital $\mathrm{B}$, and $122(6.58 \%)$ from Hospital C. The mean age was $31.83 \pm 6.68$ years and work tenure was $8.15 \pm 6.24$ years. There were significant differences in gender, age, and work tenure between hospitals (Table 1).

\section{Comparing the core competencies with the public norms}

The two competencies of team cohesion and customer relationships for the nurses working at each of the 3 hospitals were significantly superior to the corresponding public norms (Table 2). The competency of empathy was significantly superior to that of the public norm only for nurses working at Hospital A.

\section{The same factors are retained}

Four factors (teamwork, independence, communication, sympathy) were extracted from the 15 core components using EFA. The factor of sympathy, which has the highest community value, indicates that the unique core component can be presented by the sympathy factor. The coefficients of Cronbach's a was 0.68 and the DC for teamwork was 0.71 (>0.67), which indicated unidimensionality beyond the $95 \% \mathrm{CI}$ (Table 3).

\section{PLS analysis and comparisons between hospitals}

Four factors (teamwork, independence, communication, sympathy) were examined using PLS analysis to confirm the prediction 
Table 1. Descriptive statistics and analysis of the differences in the demographic variables of the nurses.

\begin{tabular}{|c|c|c|c|c|c|c|c|}
\hline Variables & Total & Hospital_A & Hospital_B & Hospital_C & & & Post hoc \\
\hline & $\mathrm{n}(\%)$ or $\pm \mathrm{SD}$ & $\mathrm{n}(\%)$ or $\pm \mathrm{SD}$ & $\mathrm{n}(\%)$ or $\pm \mathrm{SD}$ & $\mathrm{n}(\%)$ or $\pm \mathrm{SD}$ & $\mathrm{F} / \chi^{2}$ & $\mathrm{p}$ & Test \\
\hline Count & 1855 & $1156(62.32)$ & $577(31.11)$ & $122(6.58)$ & & & \\
\hline Gender & & & & & 32.64 & $<0.001^{*}$ & \\
\hline Male & $69(3.72)$ & $24(2.08)$ & $43(7.45)$ & $2(1.64)$ & & & \\
\hline Female & $1786(96.28)$ & $1132(97.92)$ & $534(92.55)$ & $120(98.36)$ & & & \\
\hline Age (years) & $31.83 \pm 6.68)$ & $31.39 \pm 6.48$ & $32.70 \pm 7.28$ & $31.89 \pm 4.98$ & 7.42 & $<0.001^{*}$ & $\mathrm{~B}>\mathrm{A}$ \\
\hline \multicolumn{8}{|l|}{ Marriage } \\
\hline Single & $1349(72.72)$ & $847(73.27)$ & $413(71.5) 8$ & $89(72.95)$ & 0.56 & 0.76 & \\
\hline Married & $506(27.28)$ & $309(26.73)$ & $164(28.42)$ & $33(27.05)$ & & & \\
\hline Education & & & & & 10.50 & $0.03 *$ & \\
\hline Senior High School & $147(7.92)$ & $86(7.44)$ & $53(9.19)$ & $8(6.56)$ & & & \\
\hline College & $1640(88.41)$ & $1016(87.89)$ & $512(88.73)$ & $112(91.80)$ & & & \\
\hline Master's Degree & $68(3.67)$ & $54(4.67)$ & $12(2.08)$ & $2(1.64)$ & & & \\
\hline Work Tenure (years) & $8.15 \pm 6.24$ & $7.84 \pm 6.05$ & $8.93 \pm 6.82$ & $7.35 \pm 4.65$ & 6.98 & $<0.001^{*}$ & $\mathrm{~B}>\mathrm{A}, \mathrm{B}>\mathrm{C}$ \\
\hline Position & & & & & 1.37 & 0.50 & \\
\hline Member & $1491(80.38)$ & $925(80.02)$ & $463(80.24)$ & $103(84.43)$ & & & \\
\hline Chief & $364(19.62)$ & $231(19.98)$ & $114(19.76)$ & $19(15.57)$ & & & \\
\hline
\end{tabular}

Table 2. Comparison of the 15 core competencies between the sample and the public norms.

\begin{tabular}{|c|c|c|c|c|c|c|c|}
\hline \multirow[b]{2}{*}{ Dimension } & \multirow{2}{*}{$\begin{array}{c}\text { Public } \\
\text { Mean } \pm \text { SD }\end{array}$} & \multicolumn{2}{|c|}{ Hospital_A $(n=1156)$} & \multicolumn{2}{|c|}{ Hospital_B $(n=577)$} & \multicolumn{2}{|c|}{ Hospital_C $(n=122)$} \\
\hline & & Mean \pm SD & $t$ & Mean \pm SD & $t$ & Mean \pm SD & $t$ \\
\hline Achievement & $61 \pm 12.21$ & $57.19 \pm 13.41$ & $-7.14^{*}$ & $57.00 \pm 13.21$ & $-6.32 *$ & $56.89 \pm 12.73$ & $-3.06^{*}$ \\
\hline Job control & $75 \pm 16.12$ & $75.14 \pm 14.45$ & 0.22 & $72.64 \pm 15.72$ & $-3.92 *$ & $74.69 \pm 15.03$ & -0.23 \\
\hline Team cohesion & $73 \pm 13.45$ & $76.75 \pm 13.49$ & $6.68^{*}$ & $75.94 \pm 13.45$ & $4.69 *$ & $79.11 \pm 11.97$ & $4.72 *$ \\
\hline Conscientiousness & $72 \pm 12.31$ & $70.22 \pm 12.69$ & -3.42 & $68.42 \pm 12.44$ & $-6.55^{*}$ & $70.67 \pm 12.45$ & -1.03 \\
\hline Executive ability & $75 \pm 12.59$ & $74.03 \pm 13.89$ & -1.76 & $71.16 \pm 14.17$ & $-6.58^{*}$ & $70.52 \pm 13.31$ & $-3.22 *$ \\
\hline Communication & $66 \pm 13.25$ & $63.81 \pm 13.37$ & $-3.96^{*}$ & $63.56 \pm 13.65$ & $-4.20^{*}$ & $62.39 \pm 14.27$ & $-2.84 *$ \\
\hline Interrelationship & $64 \pm 13.62$ & $57.48 \pm 13.14$ & $-11.71^{*}$ & $57.73 \pm 12.56$ & $-8.56^{*}$ & $57.26 \pm 14.7$ & $-4.74 *$ \\
\hline Empathy & $63 \pm 11.28$ & $64.09 \pm 10.3$ & $2.43 *$ & $63.81 \pm 11.06$ & 1.83 & $64.44 \pm 10.66$ & 1.52 \\
\hline Self-enhancement & $63 \pm 14.88$ & $55.77 \pm 13.55$ & $-12.21 *$ & $54.92 \pm 12.89$ & $-10.64 *$ & $56.18 \pm 12.39$ & $-4.37 *$ \\
\hline Adaptability & $74 \pm 13.62$ & $68.81 \pm 15.25$ & $-8.62 *$ & $66.72 \pm 15.47$ & $-9.98^{*}$ & $67.45 \pm 15.65$ & $-3.96 *$ \\
\hline Stress tolerance & $78 \pm 14.27$ & $76.48 \pm 13.84$ & $-2.59^{*}$ & $75.36 \pm 14.35$ & $-4.49^{*}$ & $73.84 \pm 14.84$ & $-3.16^{*}$ \\
\hline Optimism & $68 \pm 14.08$ & $64.67 \pm 15.41$ & $-5.42 *$ & $62.97 \pm 15.98$ & $-7.39^{*}$ & $65.59 \pm 15.58$ & -1.56 \\
\hline Analytical thinking & $67 \pm 12.79$ & $63.46 \pm 13.12$ & $-6.55^{*}$ & $62.61 \pm 13.82$ & $-7.19^{*}$ & $62.48 \pm 14.39$ & $-3.33^{*}$ \\
\hline Creativity & $66 \pm 13.76$ & $60.90 \pm 13.42$ & $-9.02 *$ & $60.81 \pm 14.28$ & $-7.70^{*}$ & $60.70 \pm 13.27$ & $-3.77 *$ \\
\hline Customer relationships & $70 \pm 12.00$ & $71.15 \pm 11.71$ & $2.34 *$ & $71.31 \pm 11.74$ & $2.62 *$ & $72.83 \pm 11.4$ & $2.60 *$ \\
\hline
\end{tabular}

Table 3. Factor analysis and community comparison. EV: $2.61=3.22 / 1.24,1.04=1.24 / 1.18$, Ratio: $2.50=2.61 / 1.04, \mathrm{DC}=2.50 /(1+2.50)$.

\begin{tabular}{|c|c|c|c|c|c|}
\hline Dimension & Teamwork & Independence & Communication & Sympathy & Community \\
\hline Optimism & 0.68 & & & & 0.49 \\
\hline Stress tolerance & 0.62 & & & & 0.41 \\
\hline Team cohesion & 0.54 & & & & 0.36 \\
\hline Adaptability & 0.52 & & & & 0.51 \\
\hline Customer relationship & 0.51 & & & & 0.36 \\
\hline Job control & 0.46 & & & & 0.29 \\
\hline Interrelationship & 0.40 & & & & 0.29 \\
\hline Executive ability & 0.40 & & & & 0.32 \\
\hline Achievement & & 0.67 & & & 0.56 \\
\hline Conscientiousness & & 0.58 & & & 0.56 \\
\hline Self-enhancement & & 0.52 & & & 0.40 \\
\hline Analytical thinking & & 0.51 & & & 0.38 \\
\hline Creativity & & & 0.75 & & 0.62 \\
\hline Communication & & & 0.44 & & 0.40 \\
\hline Empathy & & & & 0.84 & 0.72 \\
\hline Cronbach's & 0.68 & & & & \\
\hline Principal component & 1 & 2 & 3 & 4 & \\
\hline Eigenvalue (EV) & 3.22 & 1.24 & 1.18 & 1.04 & \\
\hline Ratio across EV & 2.61 & 1.04 & & & \\
\hline Final Ratio & 2.5 & & & & \\
\hline Dimension Coefficient (DC) & 0.71 & & & & \\
\hline
\end{tabular}


effect on nurse job performance. The teamwork property is used to predict nurse job performance in this study ( $t$ statistic: 4.789 [> 1.96]) (Figure 1). However, only $3 \%$ of the variance can be explained by these four factors.

Teamwork is associated with nurse performance in Hospitals $\mathrm{A}$ and $\mathrm{B}$ but not in Hospital C. There are no significant differences between the path coefficients of Hospitals A and B. In contrast, the path coefficient on Hospital $C$ is significantly different from those of Hospitals A and B (Table 4).

\section{Discussion}

\section{Key findings}

We found the following that (i) the two competencies of team cohesion and customer relationships for each of the 3 hospitals were significantly superior to the corresponding public norm means, (ii) four factors (teamwork, independence, communication, sympathy) were extracted from the original 5 core components. That the factor of sympathy had the highest mean indicates that the unique core component can be presented by the sympathy factor, (iii) the teamwork factor is able to predict nurse job performance, and (iv) the path coefficient linking teamwork and nurse job performance in Hospital C (a local hospital) was significantly different from those of Hospitals A (a medical center) and B (a regional hospital). The teamwork factor can be used to predict nurse job performance only in Hospitals A and B.

Table 4. Path coefficient between Performance and Teamwork.

\begin{tabular}{|c|c|c|c|c|}
\hline Hospital & Path & SE & $\boldsymbol{t}$ & $\mathbf{p}$ \\
\hline A & 0.16 & 0.02 & 6.55 & $<0.001$ \\
\hline B & 0.17 & 0.03 & 4.83 & $<0.001$ \\
\hline C & -0.22 & 0.26 & 0.83 & 0.41 \\
\hline Overall & 0.14 & 0.04 & 7.65 & $<0.001$ \\
\hline
\end{tabular}

Table 5. Path coefficients between hospitals. The top triangle denotes t values; the bottom triangle stands for $\mathrm{p}$-value.

\begin{tabular}{|c|c|c|c|}
\hline Hospital & A & B & C \\
\hline A & & 0.19 & $3.21^{* *}$ \\
\hline B & 0.85 & & $2.60^{* *}$ \\
\hline C & $<0.001$ & 0.01 & \\
\hline
\end{tabular}
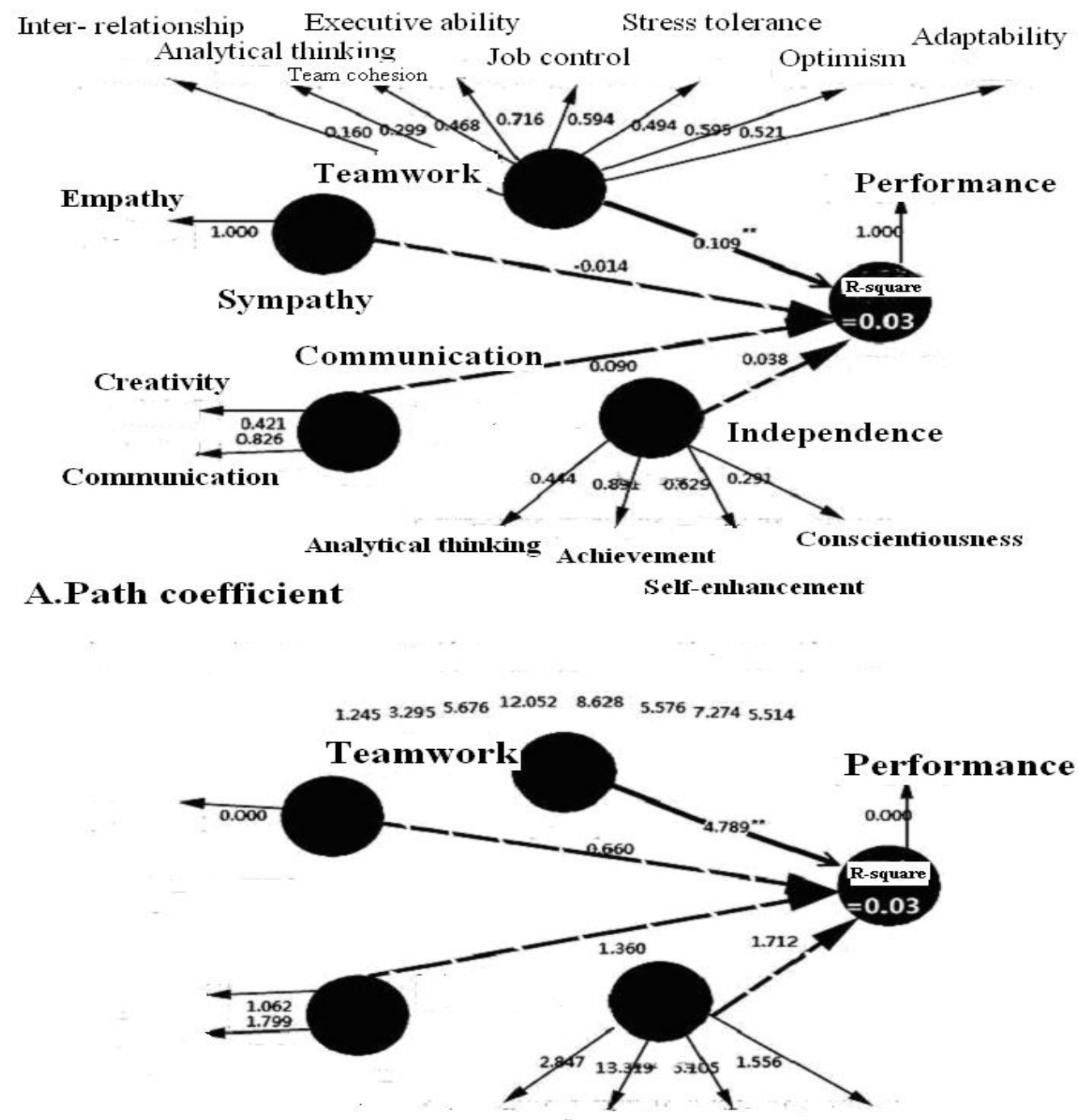

B. t-value

Figure 1. Path coefficients (on top) and t-value (on bottom) using PLS ( $\left.{ }^{* *} \mathrm{p}<0.01\right)$ 


\section{What this adds to what was known}

The outline features for the Chi-Mei Medical Group are teamwork and sympathy, according to our findings. This is because the ChiMei Medical Group recently aggressively devoted itself to drawing many initiatives into the group, such as aviation-based team resource management training courses [38,39] and the UCLA CICARE Behaviors: an acronym for a standardized evidence-based process for interactions with patients, family members, and colleagues. All healthcare employees are expected to make the connection by practicing each of the six CICARE steps with everyone on every encounter [40].-

\section{What it implies and what should be changed}

Few studies have focused on job competency in a manner similar to the focus of the current study, which verified the outline features of nurses' workplaces in a hospital. One study [22] investigated the core competencies for a professional rehabilitation-related therapist job and simply suggested that these competencies be used by hospital Human Resources Department managers for recruiting, hiring, placing, developing, and promoting nurses. We provided a method and using the EFA and PLS to evaluate employees' core components is viable for knowing their core value related to job performance in hospital nursing departments.

This study is different from previous nursing management studies that have examined nursing workforce allocation and nurse-topatient ratios in acute care general wards [9], turnover among newly graduated nurses [41], and burnout caused by heavy workloads and responsibilities [42]. Instead, we examined the personal implicit features of nurses that might lead to turnover, burnout, poor job performance, or all of these, once nurses have been placed in hospital work units that are incompatible with their personal competencies.

We showed that using the survey of the core competencies to explore the current features of an organization was useful for recruiting, hiring, placing, developing, and promoting nurses. This has not been reported in previous core competencies studies [22,43,44]. We recommend that more of these studies of the core competencies related to an organization's culture and development will be done in the future.

\section{Limitations and future studies}

The association between the core components and job performance was evident only for nurses serving at the same worksite and cannot be generalized to other types of clinical professionals or other types of workplaces when based on the specific core competence assessment that was developed by the Manpower Management Institute study [35].

The promising PLS has been considered as one of the 2nd generation statistics $[45,46]$. The variance explanation ratio (i.e., the $\mathrm{R}^{2}$ in the regression analysis) was small, about $3 \%$, which is substantially less than the expected level of $\geq 25 \%$ [47]. The limitation of weak prediction power found in this study should not lead to frustration or affect future research: both team resource management and CICARE were new programs for the Chi-Mei Medical Group. We expect the variance explanation ratio to increase over time.

Another limitation is the finding that the path coefficient linking teamwork and nurse job performance in Hospital C was significantly lower than in Hospitals A and B. This can be attributed to the small sample size $(n: C=173, A=1290$, and $B=686)$. We cannot infer that team resource management and CICARE are not successful enough to associate with the assessment of job performance.

\section{Conclusion}

Based on the findings of the present study, we recommend that the explicit core competencies should be periodically cultivated and surveyed for healthcare workers to investigate whether using them to predict job performance has been closely linked and associated with hospital policy, such as have team resource management and CICARE training courses. The core competencies associated with hospital policy have been beneficial for other hospital Human Resources Departments and for patients in their hospitals.

\section{References}

1. Judith A, Oulton M (2006) The global nursing shortage: An overview of issues and actions. Policy Politics Nursing Practice 7: 4S-39S.

2. Dembe AE, Delbos R, Erickson JB (2009) Estimates of injury risks for healthcare personnel working night shifts and long hours. Quality and Safety in Health Care 18: 336-340

3. Su SF, Liu PE, Su HY (2010) The relationships among the nurse staffing, negative patient outcomes and mortality. Cheng Ching Medical Journal 6: 36-43.

4. Carayon P, Gurses P (2005) A human factors engineering conceptual framework of nursing workload and patient safety in intensive care units. Intensive and Critical Care Nursing 21: 284-301.

5. Hugonnet S, Chevrolet JC, Pittet D (2007) The effect of workload on infection risk in critically ill patients. Crit Care Med 35: 76-81. [Crossref]

6. Stone PW, Mooney-Kane C, Larson EL, Horan T, Glance LG, et al. (2007) Nurse working conditions and patient safety outcomes. Medical Care 45: 571-578.

7. Dunton N, Gajewski B, Taunton RL, Moore J (2004) Nurse staffing and patient falls on acute care hospital units. Nursing Outlook 52: 53-58.

8. Rafferty AM, Clarke SP, Coles J, Ball J, James P, et al. (2007) Outcomes of variation in hospital nurse staffing in English hospitals: Cross-sectional analysis of survey data and discharge records. International Journal of Nursing Studies 44: 175-182.

9. Lin CB, Huang HY, Lu MS (2013) The development of nursing workforce allocation standards for acute care general wards in Taiwan. The Journal of Nursing Research 21: 298-306.

10. Cofsky KM (1993) Critical keys to competency-based pay. Comp Benef Rev 25: 46-52

11. Rothwell WJ, Lindholm JE (1999) Competency identification, modeling and assessment in the USA. Int J Train Dev 3: 90-105.

12. Spencer LM, Spencer SM (1993) Competence at work: model for superior performance. New York: John Wiley \& Sons pp. 9-15.

13. Jennings L, Skovholt TM (1999) The cognitive, emotional, and relational characteristics of master therapists. J Couns Psychol 46: 3-11.

14. Armstrong M (2009) Armstrong's handbook of human resource management practice. (11th Edn) London: Kogan pp. 201-217.

15. Lievens F, Sanchez JI, De Corte WD (2004) Easing the inferential leap in competency modeling: the effects of task-related information and subject matter expertise. Pers Psychol 57:881-904

16. Zhu Y, Chen I, Warner M (2000) HRM in Taiwan: an empirical case study. HRM 10 $32-44$.

17. Wanberg CR, Kanfer R, Rotundo M (1999) Unemployed Individuals: motives, jobsearch competencies, and job-search constraints as predictors of job seeking and reemployment. J Appl Psychol 84: 897-910.

18. Lievens F, Sanchez JI (2007) Can training improve the quality of inferences made by raters in competency modeling? A quasi-experiment. J Appl Psychol 92: 812-819. [Crossref]

19. Levenson AR, Van der Stede WA, Cohen SG (2013) Measuring the relationship between managerial, competencies and performance. JOM 32: 360-80.

20. Andrew S, Gregory L, Cowin LS (2008) Psychometric properties of the Australian nurse competency 2000 standards. Int J Nurs Stud 45: 1512-1515.

21. Lewis R, Yarker J, Donaldson-Feilder E (2010) Using a competency-based approach to identify the management behaviors required to manage workplace stress in nursing: a critical incident study. Int J Nurs Stud 47: 307-313. 
22. Wu HM, Yuan KS, Su DCJ, Chou W (2013) Investigating the core competencies for rehabilitation related therapists in three hospitals belonging to a medical association in southern Taiwan. Tw J Phys Med Rehabil 41: 203-213.

23. Chin WW (1998) The partial least squares approach for structural equation modeling. In: Marcoulides, G.A. (Ed.), Modern Methods for Business Research. Lawrence Erlbaum Associates, London pp. 295-336.

24. Haenlein M, Kaplan AM (2004) A beginner's guide to partial least squares analysis Understanding Statistics 3: 283-297.

25. Hair JF, Hult GTM, Ringle CM, Sarstedt M (2014) A Primer on Partial Least Squares Structural Equation Modeling (PLS-SEM). Thousand Oaks: Sage.

26. Wold H (1981) The fix-point approach to interdependent systems. Amsterdam: North Holland.

27. Ringle CM, Sarstedt M, Straub DW (2012) A critical look at the use of PLS-SEM in MIS quarterly. MIS Quarterly 36: iiixiv.

28. Hair JF, Sarstedt M, Ringle CM, Mena JA (2012) An assessment of the use of partial least squares structural equation modeling in marketing research. Journal of the Academy of Marketing Science 40: 414-433.

29. Hair JF, Sarstedt M, Pieper TM, Ringle CM (2012) The use of partial least squares structural equation modeling in strategic management research: A review of pas practices and recommendations for future applications. Long Range Planning 45: 320340 .

30. Lee L, Petter S, Fayard D, Robinson S (2011) On the use of partial least squares path modeling in accounting research. International Journal of Accounting Information Systems 12: 305-328.

31. Sarstedt M, Ringle CM, Smith D, Reams R, Hair JF (2014) Partial least squares structural equation modeling (PLS-SEM): A useful tool for family business researchers. Journal of Family Business Strategy 5: 105-115.

32. Peng DX, Lai F (2012) Using partial least squares in operations management research: A practical guideline and summary of past research. Journal of Operations Management 30: 467-480

33. Sosik JJ, Kahai SS, Piovoso MJ (2009) Silver Bullet or Voodoo Statistics? A primer for using the partial least squares data analytic technique in group and organization research. Group Organization Management 34: 5-36.
34. Astrachana CB, Patelb VK, Wanzenriedc GA (2014) Comparative study of CB-SEM and PLS-SEM for theory development in family firm research. Journal of Family Business Strategy 5: 116-128.

35. 1111 manpower bank (2014) The assessment system tool of the nine job competence stars.

36. Schmidt FL, Hunter JE (1998) The validity and utility of selection methods in personne psychology: practical and theoretical implication of 85 years of research findings. Psychol Bull 124: 262-274

37. Chien TW (2012) Cronbach's Alpha with the Dimension Coefficient to Jointly Assess a Scale's Quality. Rasch Measurement Transactions 26: 1379.

38. De Korne DF, Van Wijngaarden JD, Van Dyck C, Hiddema UF, Klazinga NS (2014) Evaluation of aviation-based safety team training in a hospital in The Netherlands. $J$ Health Organ Manag 28: 731-53.

39. Hsu YC, Jerng JS, Chang CW, Chen LC, Hsieh MY, et al. (2014) Integrating team resource management program into staff training improves staff's perception and patient safety in organ procurement and transplantation: the experience in a universityaffiliated medical center in Taiwan. BMC Surg 14: 51.

40. https://www.uclahealth.org/Patient-Experience/Pages/cicare.aspx.

41. Chang HL, Lu MS, Lin CF (2010) Factors related to new nursing staff turnover rates. The Journal of Health Sciences 12: 3.

42. Lee HF, Chien TW, Yen M (2013) Examining Factor Structure of Maslach Burnout Inventory among Nurses in Taiwan. Journal of Nursing Management 21: 648-656.

43. Andrew S, Gregory L, Cowin LS (2008) Psychometric properties of the Australian nurse competency 2000 standards. Int J Nurs Stud 45: 1512-1515.

44. Lewis R, Yarker J, Donaldson-Feilder E (2010) Using a competency-based approach to identify the management behaviors required to manage workplace stress in nursing: a critical incident study. Int J Nurs Stud 47: 307-313.

45. Fornell GA (1985) second generation of mltivariate analysis: classification of methods and implications for marketing research. Division of Research, Graduate School of Business Administration, The University of Michigan 414: 1-62.

46. Hair JF, Hult GTM, Ringle CM, Sarstedt M (2014) A Primer on Partial Least Squares Structural Equation Modeling (PLS-SEM). Thousand Oaks: Sage.

47. Wong K (2015) Partial Least Squares Structural Equation Modeling (PLS-SEM) Techniques Using SmartPLS. Marketing Bulletin, Techynical Note.

Copyright: $(02017$ Chien TW. This is an open-access article distributed under the terms of the Creative Commons Attribution License, which permits unrestricted use, distribution, and reproduction in any medium, provided the original author and source are credited. 